\title{
sodern arianeGroup \\ VNIR AND SWIR FPA DESIGNS FOR 3MI INSTRUMENT: THERMAL, MECHANICAL AND DIMENSIONAL STABILITY CHALLENGES
}

Sodern : Xavier Chauffleur (xavier.chauffleur@sodern.fr), Gilles Marque, Antoine Weickman, Catherine Delelis, Carlos Carvalho, Salem Belmana, Alain Durieux, Serge Primet

- Two Focal Plane Assemblies for 3MI instrument on METOP-SG were developed by Sodern.

- FPAs must insure the thermal and dimensional stability of SWIR (SOFRADIR) and VNIR (e2v) detectors.

\section{MetOp - Second Generation / 3MI instrument}

- Meteorological Operational Satellite - Second Generation:

- Earth climate observation

- ESA and EUMETSAT, six satellites developed by AIRBUS-DS, in orbit from year 2021

- 3MI (Multi-Viewing Multi-Channel Multi-Polarization Imaging) instrument by LEONARDO Company:

- multi-directional: acquisition performed by forward, nadir and backward observations of the same on-ground target at different instants

- multi-spectral: 2 optical modules, SWIR and VNIR, varying spectrally from 410 to $2130 \mathrm{~nm}$

- multi-polarization: $-60^{\circ}, 0^{\circ},+60^{\circ}$
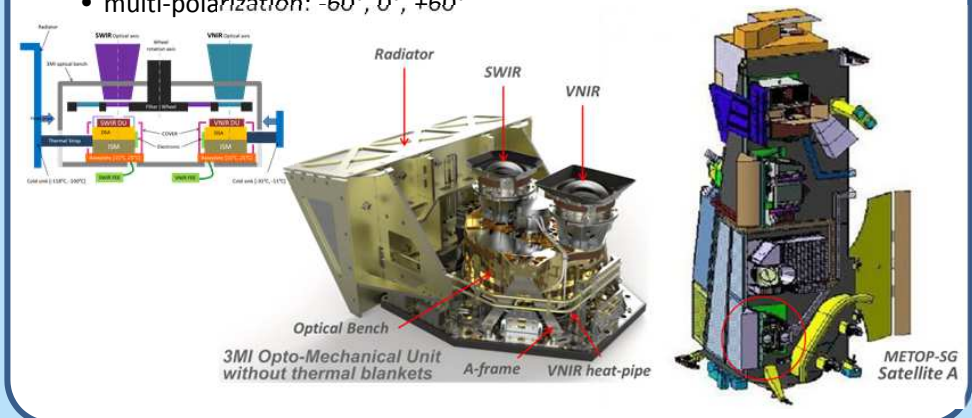

\section{FPAs specifications}

Same mechanical specifications for both FPAs:

- Compact, low mass, first mechanical eigenfrequency $>500 \mathrm{~Hz}$

- Limitation of random vibration (51gRMS) and shock level ( $1 \frac{1}{2}$ sinus $1250 \mathrm{~g}$ SWIR, $1500 \mathrm{~g}$ VNIR, 0.5ms) at detector interface

- Dimensional stability, in-plane: $\pm 1 \mu \mathrm{m}$ and out-of-plane: $\pm 4 \mu \mathrm{m}$ under gravity release, thermal strap displacement $( \pm 1 \mathrm{~mm})$, mechanical and thermal environments (tests, launch and operative).

- Input mechanical loads, out-of-plane: QSL 60g, random vib. 21gRMS, SRS 212g at $1000 \mathrm{~Hz}$

Different thermal specifications depending on:

- operating temperature of detectors

- I/F temperature

- Type of thermal control: heater for SWIR, TEC for VNIR

\begin{tabular}{|c|c|c|c|c|c|c|c|}
\hline & \multirow[b]{2}{*}{ Case } & \multirow{2}{*}{$\begin{array}{c}\text { Baseplate and } \\
\text { radiative } \\
\text { Temp. } \\
\left({ }^{\circ} \mathrm{C}\right)\end{array}$} & \multicolumn{2}{|c|}{$\begin{array}{c}\text { Cooling sink } \\
\text { (linear depending on rejected power) }\end{array}$} & \multirow{2}{*}{$\begin{array}{l}\text { Thermal control } \\
\text { Power } \\
\text { (W) }\end{array}$} & \multicolumn{2}{|c|}{ Detector } \\
\hline & & & $\begin{array}{l}\text { Temp. @oW } \\
\left({ }^{\circ} \mathrm{C}\right)\end{array}$ & $\begin{array}{l}\text { Thermal resistance } \\
(\mathrm{K} / \mathrm{W})\end{array}$ & & $\begin{array}{l}\text { Oper temp. } \\
\left({ }^{\circ} \mathrm{C}\right)\end{array}$ & $\begin{array}{l}\text { Power } \\
\text { (W) }\end{array}$ \\
\hline SWIR & Cold & 15 & -118 & 3.4 & max. $3 \mathrm{~W}$ with heater & -88.15 & 0.18 \\
\hline \multirow{2}{*}{ VNIR } & Cold & $\frac{25}{15}$ & $-\frac{-100}{-35}$ & 3.6 & & & \\
\hline & Hot & 25 & -11 & 6.2 & $\begin{array}{l}\text { max. } 2 \mathrm{~W} \text { with TEC in } \\
\mathrm{DU}\end{array}$ & -20 & $\begin{array}{c}0.14 \\
0.5 \text { (prox. electro.) }\end{array}$ \\
\hline
\end{tabular}

Main requirements:

- long time storage: series of satellites built and stored up to 15 years before launch

- Cleanliness: ISO 5, Molecular $\leq 0.5 \mathrm{E}-7 \mathrm{~g} / \mathrm{cm}^{2}$
Derived Thermal needs for SWIR, covering VNIR

o High insulation with hot parts (baseplate): $100 \mathrm{~K} / \mathrm{W}$

-ISM: 200K/W

- FLEX: 200K/W

- High coupling with cold sink

- Thermal strap: $2.7 \mathrm{~K} / \mathrm{W}$

ISM: Thermal and Mechanical Optimization

Research of architecture

Parametric Design Optimization, Pareto Diagram
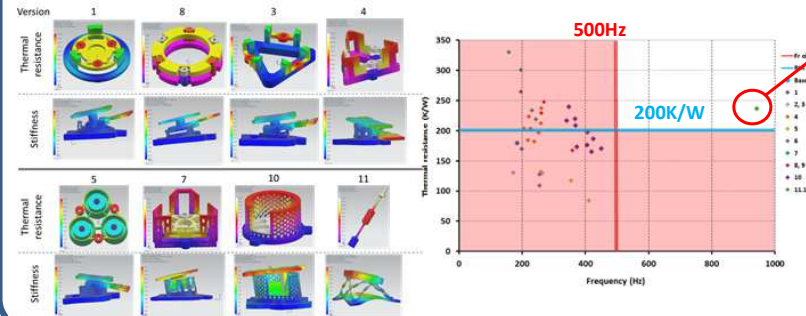

Thermal and Mechanical Optimizations

Thermal strap: low thermal resistance, low stiffnes

Copper braids permits direct integration into mechanical parts in comparison to graphite foils: less space and contact resistance.

- Measurement of single braids for parametric evaluations:

- Loop (S or U shape) is a major factor to reduce axial stiffness

- Braids with $50 \mu \mathrm{m}$ diameter strands 9 times more flexible than $150 \mu \mathrm{m}$

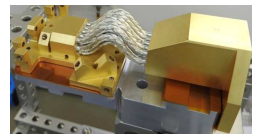

Thermal resistance of detector

SWIR design to VNIR

In addition to screwing for stability purpose, glue is added between detector and DSA to shorten thermal resistance into Kovar.
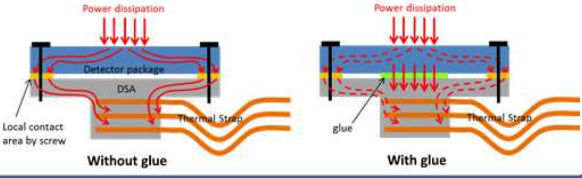

Operating temperature, thermo-elastic behavior

In-plane: the whole geometry is centered around optical axis

- position of the detector

- each of the three sets of two shafts is arranged at $120^{\circ}$

Out-of-plane: complex kinematic. With the temperature increase, two phenomena occurs:

- the baseplate inflects in the plane, the distance between the fixing points of the shafts increases, the triangle forms by two shafts caves in and the DSA goes down;

- on the contrary, the length of the shaft increase and the DSA goes up.
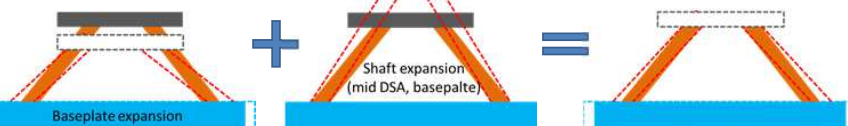

Stability

- Compromise between SWIR and VNIR on shaft geometry (angle with baseplate and length) to adapt thermal gradients according to the differences of thermal controls:

SWIR: mid case to hot case: DSA: $+0^{\circ} \mathrm{C}$ (heater regul.), baseplate: $+5^{\circ} \mathrm{C}=>-1.35 \mu \mathrm{m}$

VNIR: mid case to hot case: DSA: $+19^{\circ} \mathrm{C}$ (TEC power), baseplate: $+5^{\circ} \mathrm{C}=>+2.45 \mu \mathrm{m}$

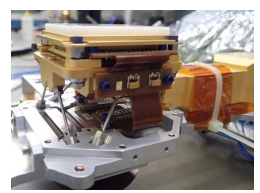

AMM and STM tests

- Validation of stability under thermal and mechanical environments: lower than $2 \mu \mathrm{m}, 3 \mathrm{D}$ machine accuracy: not sliding between shaft / DSA and baseplate because support areas are perpendicular to axe of shaft

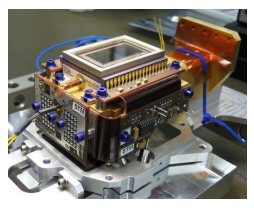

